\title{
Polyhydroxybutyrate biosynthesis in Caulobacter crescentus: molecular characterization of the polyhydroxybutyrate synthase
}

\author{
Qingsheng Qi and Bernd H. A. Rehm
}

Institut für Mikrobiologie der Westfälischen WilhelmsUniversität Münster, Corrensstrasse 3, 48149

Münster, Germany

\author{
Author for correspondence: Bernd H. A. Rehm. Tel: +49 251833 9848. Fax: +49 2518338388 \\ e-mail: rehm@uni-muenster.de
}

Caulobacter crescentus was investigated with respect to polyhydroxybutyrate (PHB) biosynthesis. Polyhydroxyalkanoate (PHA) accumulation contributing to approximately $18 \%$ of the cell dry weight was obtained in the presence of glucose. Gas chromatography-mass spectrometry and gel permeation chromatography of the purified PHA showed that this polyester was solely composed of 3-hydroxybutyrate and had a weight average molar mass of $5.5 \times 10^{5} \mathrm{~g} \mathrm{~mol}^{-1}$ and a polydispersity of 1.6. An ORF encoding a conserved, hypothetical protein which shared approximately $47 \%$ identity with the PHB synthase from Azorhizobium caulinodans was identified within the complete $C$. crescentus genomic sequence. This putative $C$. crescentus PHB synthase gene, phaC, consisted of a $2019 \mathrm{nt}$ stretch of DNA (encoding 673 aa residues), which encoded a PHB synthase with a molecular mass of approximately $73 \mathrm{kDa}$. This is currently the largest PHA synthase identified. The phaC coding region was subcloned into vector pBBR1-JO2 under lac promoter control. The resulting plasmid, pQQ4, mediated PHB accumulation in the mutant Ralstonia eutropha PHB-4 and recombinant Escherichia coli JM109(pBHR69), which produced the $\beta$-ketothiolase and acetoacetyl-CoA reductase from $R$. eutropha, contributing to approximately $62 \%$ and $6 \%$ of cell dry weight, respectively. Functional expression of the coding region of phaC was confirmed by immunoblotting and in vitro PHB synthase activity.

Keywords: polyhydroxyalkanoate, PHA synthase, PHA depolymerase

\section{INTRODUCTION}

Caulobacter crescentus is a Gram-negative, polarlyflagellated bacterium, which physiologically resembles the aerobic, chemoheterotrophic pseudomonads. The ability of C. crescentus to survive in famine conditions suggests that it may produce polyhydroxyalkanoates (PHAs), or other polymers, as carbon and energy reserves. Polyhydroxybutyrate (PHB) has already been shown to be a product of Caulobacter spp. metabolism during nitrogen and phosphate starvation conditions (Poindexter, 1981).

Abbreviations: CDW, cell dry weight; GC-MS, gas chromatography-mass spectrometry; GPC, gel permeation chromatography; PHA, polyhydroxyalkanoate; PHB, polyhydroxybutyrate.

The GenBank accession numbers for the phaC and phaZ sequences reported in this paper are AY007313 and AF311864, respectively.
PHAs are currently under intensive investigation because of their inherent property as biodegradable thermoplastics. PHA synthases, which use CoA thioesters of $(R)$-3-hydroxyalkanoates as substrates and catalyse the polymerization of these monomers to PHA with concomitant release of CoA, represent the key enzymes of PHA biosynthesis. More than 40 PHA synthase genes have been assigned and characterized (Rehm \& Steinbüchel, 1999, 2001a), and their protein products can be broadly arranged into three different classes based on their subunit composition and substrate specificities. Class I synthases are active towards shortchain-length $(R)$-hydroxyacyl-CoA, consisting of three to five carbon atoms, and are represented by the PHA synthase of Ralstonia eutropha. Class II is represented by the PHA synthase of Pseudomonas aeruginosa which is active towards medium-chain-length $(R)-3$ hydroxyacyl-CoA, containing 6 to $14 \mathrm{C}$ atoms. PHA 
synthases of class I and class II are composed of a single subunit, whereas class III PHA synthases are composed of two non-identical subunits. Class III is represented by the Allochromatium vinosum PHA synthase, consisting of subunits $\mathrm{PhaC}$ and $\mathrm{PhaE}$, and exhibiting activity towards short-chain-length $(R)$-3-hydroxyacyl-CoA. In addition, a few bacteria, such as Aeromonas punctata (Fukui et al., 1998) and Rhodococcus ruber (Haywood et al., 1991), have been reported to have PHA synthases that are composed of one subunit which exhibits specificity for both short- and medium-chain-length $(R)$ 3-hydroxyacyl-CoA. Although numerous PHA synthase genes have been cloned and assigned, only a few PHA synthases have been purified and enzymically characterized, e.g. PHA synthases from $R$. eutropha, $A$. vinosum and $P$. aeruginosa (Gerngross et al., 1994; Liebergesell et al., 1994; Qi et al., 2000; Rehm et al., 2001a).

The PHB biosynthesis pathway of R. eutropha has been studied in detail (Peoples \& Sinskey, 1989a, b; Schubert et al., 1988). In this bacterium, the biosynthetic process is initiated by the condensation of two acetyl-CoA molecules to produce acetoacetyl-CoA which is catalysed by the enzyme $\beta$-ketothiolase (EC 2.3.1.9; gene $p h b A)$. Acetoacetyl-CoA is then reduced to $(R)$ 3-hydroxybutyryl-CoA by the NADPH-dependent acetoacetyl-CoA reductase (EC 1.1.1.36; gene $p h b B$ ). These enzymes have also been found and studied in several other PHB-accumulating bacteria.

The synthesis of medium-chain-length PHAs relies mainly on the $\beta$-oxidation pathway (Langenbach et al., 1997; Qi et al., 1997, 1998) when fatty acids are used as carbon source, or on fatty acid de novo synthesis when other non-related carbon sources, such as gluconate, were employed (Rehm et al., 1998; Fiedler et al., 2000; Hoffmann et al. 2000a, 2000b). Meanwhile, various medium-chain-length PHA biosynthetic pathways have been established in recombinant bacteria, which recruit intermediates of fatty acid metabolism (Rehm et al., 2001b; Rehm \& Steinbüchel, 2001b).

In this study we describe the capability of C. crescentus DSM $4727^{\mathrm{T}}$ to produce PHB in the presence of excess carbon source. The PHB synthase gene and corresponding enzyme of C. crescentus DSM $4727^{\mathrm{T}}$ were characterized by heterologous functional expression in a PHB-negative mutant of R. eutropha and in Escherichia coli, and by analysis of the in vitro PHB synthase activity. Furthermore, evidence for the re-utilization of PHB by an intracellular PHB depolymerase was also obtained.

\section{METHODS}

Bacterial strains, plasmids, and culture conditions. $C$. crescentus DSM $4727^{\mathrm{T}}$ was cultivated at $30^{\circ} \mathrm{C}$ in Caulobacter medium (CM), which contains $2.0 \mathrm{~g}$ Bacto-peptone, $1.0 \mathrm{~g}$ yeast extract and $0.2 \mathrm{~g} \mathrm{MgSO}_{4} .7 \mathrm{H}_{2} \mathrm{O}$ per litre. Glucose $(1 \%$ $\mathrm{w} / \mathrm{v})$ or other carbon sources $(0.2 \% \mathrm{w} / \mathrm{v})$ were added as appropriate. E. coli strains were cultivated at $37{ }^{\circ} \mathrm{C}$ in Luria-Bertani broth (LB; Sambrook et al., 1989) or M9 (minimal medium; Sambrook et al., 1989) containing the carbon sources, supplements and antibiotics indicated. $R$. eutropha strains were cultivated in nutrient broth (Sambrook et al., 1989) medium or mineral salt medium (MM; Schlegel et al., 1970) supplemented with $1 \%$ (w/v) gluconate. Kanamycin $\left(500 \mu \mathrm{g} \mathrm{ml}^{-1}\right)$ or ampicillin $\left(100 \mu \mathrm{g} \mathrm{ml}^{-1}\right)$ were added if required. The strains and plasmids used in this study are listed in Table 1.

Isolation and manipulation of DNA. Chromosomal DNA was prepared from C. crescentus DSM 4727 ${ }^{\mathrm{T}}$ according to the method described by Mak \& Ho (1993). PCR was performed using Vent DNA polymerase (New England Biolabs) and oligonucleotide primers for the N-terminus $\left(5^{\prime}\right.$ GCGGATCCGGAGGAAACCCCATGGCCACG-3') and Cterminus (3'-CGGAATTCTCAGGGTTGTGACTTTCACAG-5') of the putative $p h a C$ coding region. The N-terminus primer contained a BamHI site at its 5' end (underlined); the C-terminus primer contained an EcoRI site at its $3^{\prime}$ end (underlined). The resulting PCR product was subcloned into the respective sites of vector pBBR1-JO2 (Dr H. Priefert, Institut für Mikrobiologie der Westfälischen WilhelmsUniversität Münster, Germany) to generate pQQ4. New constructs were confirmed by DNA sequencing (MWG Biotech). The DNA sequences of the coding regions of $p h a C$ and $p h a Z$ of C. crescentus, and their protein sequences, have been deposited in GenBank under the accession numbers AY007313 and AF311864, respectively. Conjugation of $R$. eutropha $\mathrm{PHB}^{-} 4$ with E. coli $\mathrm{S} 17-1$ harbouring broad-hostrange plasmids was performed as described by Friedrich et al. (1981). All other genetic techniques employed were performed as described by Sambrook et al. (1989).

Analysis of the PHA in cells. PHAs were analysed by GC. Cells were harvested by centrifugation at $10000 \mathrm{~g}$ for $15 \mathrm{~min}$. The cells were then washed twice in saline solution $(0.9 \%, \mathrm{w} / \mathrm{v}$, $\mathrm{NaCl}$ ) and lyophilized overnight. About 5-10 mg dry cells were subjected to methanolysis in the presence of $15 \%(\mathrm{v} / \mathrm{v})$ sulfuric acid. The resulting methyl esters of the respective 3hydroxyalkanoates were assayed by a GC system (PerkinElmer) equipped with a $0.5 \mu \mathrm{m}$ Permphase PEG25 Mx capillary column as described by Brandl et al. (1988).

Isolation of the PHA from lyophilized cells. PHA was extracted from lyophilized cells using chloroform extraction in a Soxhlet apparatus and was subsequently precipitated with 10 vols ethanol. The precipitate was dissolved in chloroform and ethanol-precipitated again in order to obtain highly purified PHA.

Gas chromatography-mass spectrometry (GC-MS). Purified polymer, prepared as described above, was dissolved in chloroform (5 mg PHA ml $\mathrm{m}^{-1}$ ), and $3 \mu \mathrm{l}$ was injected into a GC-MS instrument (model 6890; Hewlett Packard). The column and temperature profile used for GC analysis were as described by Schubert et al. (1991).

Gel permeation chromatography (GPC). Molecular mass analysis was conducted with purified PHA, which was dissolved in chloroform (5-10 $\left.\mathrm{mg} \mathrm{PHA} \mathrm{ml}^{-1}\right)$ and introduced into a GPC system (Waters). The GPC system was equipped with Styragel Guard and a Styragel HR3-6 separation column. The eluted polymer was detected with a differential refractometer (model 410; Waters). A polystyrene molecular mass standard (Sigma) with a narrow range of polydispersity was employed for calibration of the system.

Protein content. The protein content was obtained by the Bradford method, as described by Laemmli (1970).

Electrophoresis of proteins. SDS-PAGE $(12.5 \%, \mathrm{w} / \mathrm{v})$ was performed in a vertical slab gel electrophoresis apparatus, as described by Sambrook et al. (1989). 
Table 1. Bacterial strains and plasmids used in this study

\begin{tabular}{|c|c|c|}
\hline Plasmid or strain & Relevant characteristic & Source or reference \\
\hline \multicolumn{3}{|l|}{ Strains } \\
\hline C. crescentus & Wild-type & DSMZ $4727^{\mathrm{T}}$ \\
\hline R. eutropha $\mathrm{H} 16$ & Wild-type & DSMZ 428 \\
\hline R. eutropha $\mathrm{PHB}^{-} 4$ & $\mathrm{PHB}^{-} 4$ mutant of $\mathrm{R}$. eutropha $\mathrm{H} 16$ & Schlegel et al. (1970) \\
\hline E. coli JM109 & $\begin{array}{l}\left.\text { recA1 end } A 1 \text { gyrA96 thi-1 hsdR17( } \mathrm{r}_{\mathrm{k}}^{-} \mathrm{m}_{\mathrm{k}}^{-}\right) \text {supE44 } \\
\text { relA1 } \Delta(\text { lac-pro } A B)\left(\mathrm{F}^{\prime} \text { proAB } \text { lacl }^{\mathrm{q}} \mathrm{Z} \Delta \mathrm{M} 15\right)\end{array}$ & \\
\hline E. coli $\mathrm{S} 17-1$ & $\begin{array}{l}\text { proA thi-1 recA, harbouring the tra genes of } \\
\text { plasmid RP4 in the chromosome }\end{array}$ & Simon et al. (1983) \\
\hline \multicolumn{3}{|l|}{ Plasmids } \\
\hline pBBR1-JO2 & $\begin{array}{l}\text { pBBR1MCS-2, containing the polylinker from } \\
\text { pBluescript SK }\end{array}$ & $\begin{array}{l}\text { Kovach et al. (1995); } \\
\text { Dr H. Priefert }\end{array}$ \\
\hline pPS1 & $\begin{array}{l}\text { pBBR } 1 \text { MCS-2, containing the coding region of } \\
\text { phaC from } R \text {. eutropha }\end{array}$ & This study \\
\hline pQQ4 & $\begin{array}{l}\text { pBBR1-JO2, containing coding region of } p h a C \\
\text { from C. crescentus }\end{array}$ & This study \\
\hline pBHR69 & $\begin{array}{l}\text { pBluescript } \mathrm{SK}^{-} \text {, containing } p h a B \text { and } p h a A \text { from } \\
\text { R. eutropha }\end{array}$ & $\begin{array}{l}\text { Spiekermann et al. } \\
\text { (1999) }\end{array}$ \\
\hline
\end{tabular}

Western immunoblot analysis. Western blots were performed with a semidry Fastblot apparatus (Bio-Rad) as follows. Antiserum against the PHB synthase of $R$. eutropha (anti$\mathrm{PhaC}$ ) was raised. This antiserum was applied to a nitrocellulose membrane, and an alkaline phosphatase-antibody conjugate (Sigma) was also applied to the membrane. Bound antibodies were detected using nitro blue tetrazolium chloride and the toluidine salt of 5-bromo-4-chloro-3-indolyl phosphate.

PHB synthase assay. The in vitro activity of PHB synthase in crude extracts was assayed by the DTNB [5,5'-dithiobios-(2nitrobenzoic acid)] method, as described by Valentin \& Steinbüchel (1993).

\section{RESULTS AND DISCUSSION}

\section{Analysis of PHA production by C. crescentus}

To investigate the metabolic storage compounds synthesized by C. crescentus when it is cultivated in the presence of excess carbon source, we used $\mathrm{CM}+1 \%$ $(\mathrm{w} / \mathrm{v})$ glucose or $\mathrm{CM}+0 \cdot 2 \%(\mathrm{w} / \mathrm{v})$ decanoate. After cultivation at $30^{\circ} \mathrm{C}$ for $24 \mathrm{~h}$ we observed granules in the cells under phase-contrast microscopy. The granules were mainly observed in stalked cells; the cell shape was more rod-like than vibrioid at this stage. GC-MS analysis of whole cells showed that when either glucose or decanoate was used as the carbon source, PHA was produced. CM without an additional carbon source did not mediate the formation of PHA. PHA was isolated from C. crescentus cells which had been grown in the presence of glucose. The isolated polymer was found to be composed solely of 3-hydroxybutyrate. GPC analysis of the purified polymer revealed a polydispersity of 1.6 with a weight average molar mass of $5.5 \times 10^{5} \mathrm{~g} \mathrm{~mol}^{-1}$ and a number average molar mass of $3.4 \times 10^{5} \mathrm{~g} \mathrm{~mol}^{-1}$. Time-course analysis of PHB production by C. crescentus DSM $4727^{\mathrm{T}}$ using glucose as a carbon source

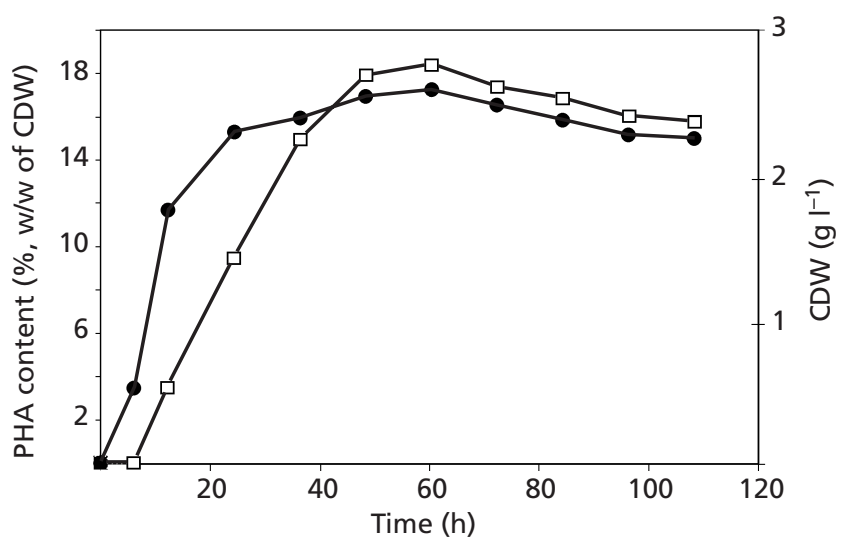

Fig. 1. Time-course analysis of PHB production ( $\square$ ) and growth curve for C. crescentus (O). PHB accumulation expressed as a percentage of CDW. Growth rate is expressed in terms of $\mathrm{g}$ CDW litre ${ }^{-1}$ growth medium.

indicated growth-associated PHB production (Fig. 1). PHB accumulated simultaneously with cell growth, and reached its maximum level after approximately $60 \mathrm{~h}$ (Fig. 1), contributing approximately $18.3 \%$ of cell dry weight (CDW) (biomass $2.5 \mathrm{~g} \mathrm{CDW}^{-1}$ ). A slight decrease in the level of CDW coincided with a small decrease in PHB content, which indicated the presence of an intracellular PHB depolymerase. Further evidence for an intracellular depolymerase was obtained by identification of a conserved hypothetical protein (Locus no. AAK22237; GI no. 13421381) within the genome sequence for C. crescentus [GenBank accession no. AE005698 (part 24 of 359); Nierman et. al, 2001] whose deduced amino acid sequence showed approximately $45 \%$ similarity to the intracellular depolymerase 


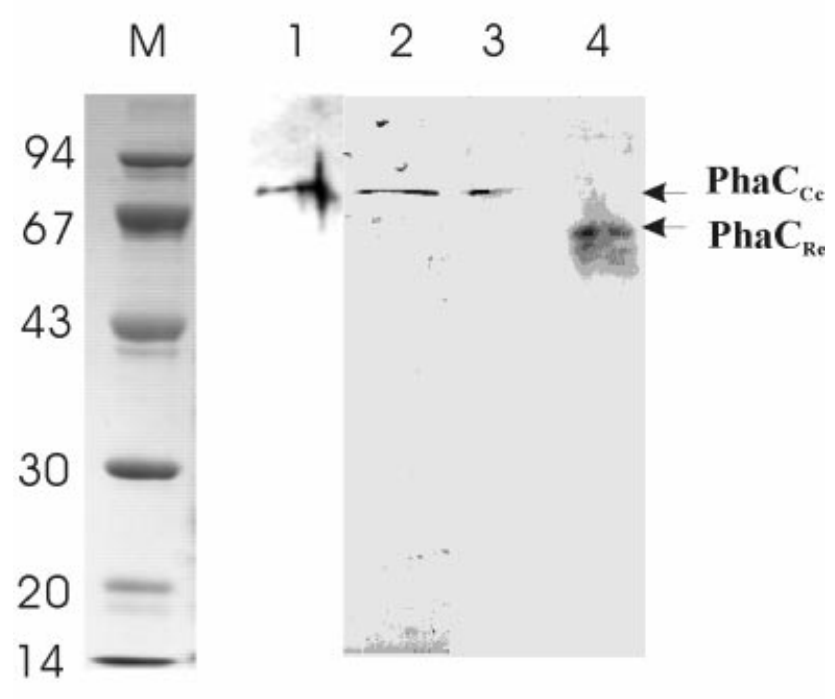

Fig. 2. Immunoblot analysis of crude extracts from $C$. crescentus, E. coli JM109(pQQ4) and R. eutropha $\mathrm{PHB}^{-} 4$ (pQQ4). Immunoblotting was performed using anti-PhaC antibodies raised against $R$. eutropha H16. Lanes: $M$, molecular mass standard; 1, R. eutropha $\mathrm{PHB}^{-} 4(\mathrm{pQQ} 4) ; 2$, E. coli JM109(pQQ4); 3 , C. crescentus; $4, R$. eutropha $\mathrm{H} 16$ (positive control). Arrows indicate the position of the $R$. eutropha PHA synthase $\left(\mathrm{PhaC}_{\mathrm{Re}}\right)$ and of the $C$. crescentus PHA synthase $\left(\mathrm{PhaC}_{\mathrm{CC}}\right)$.

of R. eutropha (Handrick et al., 2000). This putative phaZ gene encodes a protein consisting of 375 aa with a molecular mass of $41 \cdot 8 \mathrm{kDa}$.

\section{Identification of the PHB synthase gene and its expression}

Since the C. crescentus genomic DNA has been completely sequenced (www.tigr.com), we searched the genome for DNA regions homologous to PHA synthase genes. In the database we identified a 587 aa protein [Locus no. AAK23361; GI no. 13422735; accession no. AE005813 (part 139 of 359); Nierman et al., 2001] which showed $100 \%$ identity to the C-terminal end of our 673 aa $(73.6 \mathrm{kDa})$ phaC protein sequence. Although Nierman et al. (2001) tentatively named their protein poly- $\beta$-hydroxybutyrate polymerase they did not functionally characterize the region. Our data also show that they chose an inappropriate start codon for the coding region of their putative protein. A multiple alignment including the protein sequence of $p h a C$ revealed that this protein was highly homologous to other PHA synthases, with $25-47 \%$ sequence similarity to previously recognized sequences. The strongest homology was obtained with PHA synthases from Azorhizobium caulinodans (47\% identity), Rhodospirillum rubrum (46\% identity) and R. eutropha (46\% identity), suggesting that the putative PHB synthase from $C$. crescentus belongs to class I PHA synthases.

A putative lipase box $\mathrm{GX}(\mathrm{C} / \mathrm{S}) \mathrm{XG}$ was found within the PHB synthase protein sequence, in which the serine essential for the active site of the lipase was replaced by a cysteine. It also contained the conserved amino acids C319, D480 and H508 (positions relative to R. eutropha PHA synthase). Analysis of the adjacent DNA sequence regions ( $3 \mathrm{~kb}$ upstream and downstream of the respective coding region) did not indicate co-localization of $\mathrm{PHB}$ biosynthesis genes, such as $p h b A$ and $p h b B$. We amplified and cloned the putative PHB-synthase-encoding DNA region as described in Methods. Plasmid pQQ4 was introduced into E. coli JM109 and R. eutropha $\mathrm{PHB}^{-}$, and the cells were cultivated under the respective PHB accumulation conditions. SDS-PAGE and immunoblot analysis with anti-PhaC antiserum (raised against the R. eutropha protein) revealed that the putative PHB synthase gene was expressed in both E. coli JM109 and R. eutropha $\mathrm{PHB}^{-} 4$ (Fig. 2). An immunologically crossreacting protein of approximately $73 \mathrm{kDa}$ was obtained. A cross-reacting protein with an apparent molecular mass of $73 \mathrm{kDa}$ was also detected, by anti-PhaC antiserum in crude extracts of C. crescentus (Fig. 2).

\section{PHB accumulation in recombinant $R$. eutropha $\mathrm{PHB}^{-4}$ and $E$. coli}

To confirm that the putative coding region of $p h a C$ from C. crescentus encoded an active PHB synthase, phaC was expressed from the lac promoter in R. eutropha $\mathrm{PHB}^{-} 4$ and in E. coli JM109. The E. coli strains were grown in $250 \mathrm{ml}$ Erlenmeyer flasks containing $50 \mathrm{ml}$ medium with $1 \mathrm{mM}$ IPTG and $50 \mu \mathrm{g}$ kanamycin $\mathrm{ml}^{-1}$ at $37^{\circ} \mathrm{C}$ for 48 h. R. eutropha was grown in $250 \mathrm{ml}$ Erlenmeyer flasks containing $50 \mathrm{ml}$ medium and $500 \mu \mathrm{g}$ kanamycin $\mathrm{ml}^{-1}$ at $30{ }^{\circ} \mathrm{C}$ for $48 \mathrm{~h}$. PHB content was measured as a percentage of CDW. Wild-type $C$. crescentus (grown in $\mathrm{CM}+1 \%$ gluconate) demonstrated a PHB content of $18 \%$, while $R$. eutropha $\mathrm{PHB}^{-} 4$ (pQQ4) (grown in $\mathrm{MM}+1 \%$ gluconate) appeared to be complemented by the presence of the phaC gene, resulting in PHB accumulation contributing to a PHB content of $62.4 \%$. The negative control $R$. eutropha $\mathrm{PHB}^{-} 4$ (pBBR1-JO2) (grown in $\mathrm{MM}+1 \%$ gluconate) did not mediate PHB accumulation (PHB content $<1 \%$ ). E. coli JM109(pQQ4/pBHR69), containing the genes encoding the $\beta$-ketothiolase and acetoacetyl-CoA reductase from R. eutropha (pBHR69) as well as the phaC gene (pQQ4) from C. crescentus, resulted in PHB contents of $5.2 \%$ and $5.5 \%$ when cultivated in $\mathrm{LB}+1 \%$ glucose and $\mathrm{M} 9+1 \%$ glucose, respectively. No PHB was detected for E. coli JM109(pBHR69) and E. coli JM109(pQQ4) grown in $\mathrm{LB}+1 \%$ glucose (w/v). E. coli JM109(pPS1/pBHR69), containing the $p h a C$, phaB and phaA genes from $R$. eutropha and grown in LB $+1 \%$ glucose, had a PHB content of $5 \cdot 8 \%$.

\section{Enzymic activity of the putative PHB synthase from C. crescentus}

Crude extracts of C. crescentus, recombinant $R$. eutropha $\mathrm{PHB}^{-} 4$ (pQQ4) and recombinant E. coli JM109(pQQ4) were investigated with respect to in vitro 
Table 2. In vitro PHB synthase activity of $C$. crescentus and recombinant strains of $R$. eutropha $\mathrm{PHB}^{-} 4$ and E. coli JM109

\begin{tabular}{|c|c|c|}
\hline Strain (plasmid) & $\begin{array}{c}\text { Crude extract } \\
{\left[\mathrm{mg}(\text { total protein }) \mathrm{ml}^{-1}\right]}\end{array}$ & $\begin{array}{c}\text { PHB synthase activity } \\
{\left[\mathrm{mU}(\mathrm{mg} \text { total protein })^{-1}\right]^{*}}\end{array}$ \\
\hline C. crescentus DSM $4727^{\mathrm{T}}$ & $2 \cdot 56$ & $59 \cdot 5$ \\
\hline R. eutropha $\mathrm{PHB}^{-} 4(\mathrm{pBBR} 1-\mathrm{JO} 2)$ & $2 \cdot 44$ & $\mathrm{ND}$ \\
\hline R. eutropha $\mathrm{PHB}^{-} 4$ (pQQ4) & $2 \cdot 19$ & 304 \\
\hline E. coli JM109(pBBR1-JO2) & $2 \cdot 75$ & ND \\
\hline E. coli JM109(pQQ4) & $2 \cdot 95$ & $54 \cdot 5$ \\
\hline
\end{tabular}

ND, Not detectable.

* One unit of activity is defined as $1 \mu \mathrm{mol} \mathrm{CoA}$ released $\min ^{-1}$ under the assay conditions. $(R, S)-3$ hydroxybutyryl-CoA was used as the substrate.

PHB synthase activity, employing 3-hydroxybutyrylCoA as substrate (Table 2). In C. crescentus, a PHB synthase activity of $59 \cdot 5 \mathrm{mU}(\mathrm{mg} \text { total protein })^{-1}$ was obtained. The PHB synthase activity in crude extracts of recombinant $R$. eutropha $\mathrm{PHB}^{-} 4$ (pQQ4) and recombinant E. coli JM109(pQQ4) was $304 \mathrm{mU}$ (mg total protein $)^{-1}$ and $54.5 \mathrm{mU}$ (mg total protein $)^{-1}$, respectively. As expected, no activity was detected for the control strains, carrying only vector pBBR1-JO2. Hence, the study indicated that the PHB synthase shows in vitro activity in C. crescentus and that the enzyme is functionally produced in R. eutropha $\mathrm{PHB}^{-} 4$ and E. coli JM109.

The PHB synthase from C. crescentus represents the largest PHA synthase currently known, with a molecular mass of $73.6 \mathrm{kDa}$. The multiple alignment of all PHA synthases indicated that the $\mathrm{N}$-terminus of the protein is subject to residue variation. The 85 amino acids from the $\mathrm{N}$-terminus of C. crescentus PHB synthase have almost no homology to other PHA synthases. Conserved residues were identified which might play an important role in the catalytic mechanism, e.g. H590 (H508 of the R. eutropha PHA synthase), a residue which is supposed to be the general base catalyst that activates the nucleophile C406 (C319 of the $R$. eutropha PHB synthase) (Jia et al., 2000; Jia et al., 2001). The C406 in the lipase-box-like region is supposed to be directly involved in covalent catalysis. D512 (D480 of the $R$. eutropha PHA synthase) might function as a general base catalyst in activation of the 3-hydroxy group of 3hydroxybutyryl-CoA for nucleophilic attack on the covalently linked thioester intermediate. The functional assignment of catalytic amino acid residues was based on mutational studies with the $R$. eutropha and $A$. vinosum PHA synthase (Hoppensack et al., 1999; Jia et al., 2000, 2001).

\section{ACKNOWLEDGEMENTS}

The authors are indebted to Dr Alexander Steinbüchel for valuable scientific discussion and constructive criticism. We gratefully acknowledge construction of plasmid pPS1 by Patricia Spiekermann. This study was partially supported by grant Re 1097/4-1 from the Deutsche Forschungsgemeinschaft.

\section{REFERENCES}

Brandl, H., Gross, R. A., Lenz, R. W. \& Fuller, R. C. (1988). Pseudomonas oleovorans as a source of poly( $\beta$-hydroxyalkanoates) for potential applications as biodegradable polyesters. Appl Environ Microbiol 54, 1977-1982.

Fiedler, S., Steinbüchel, A. \& Rehm, B. H. A. (2000). PhaGmediated synthesis of poly(3-hydroxyalkanoates) consisting of medium-chain-length constituents from nonrelated carbon sources in recombinant Pseudomonas fragi. Appl Environ Microbiol 66, 2117-2124.

Friedrich, B., Hogrefe, C. \& Schlegel, H. G. (1981). Naturallyoccurring genetic transfer of hydrogen-oxidizing ability between strains of Alcaligenes eutrophus. J Bacteriol 147, 198-205.

Fukui, T., Shiomi, N. \& Doi, Y. (1998). Expression and characterization of $(R)$-specific enoyl coenzyme A hydratase involved in polyhydroxyalkanoate biosynthesis by Aeromonas caviae. J Bacteriol 180, 667-673.

Gerngross, T. U., Snell, K. D., Peoples, O. P., Sinskey, A. J., Csuhai, E., Masamune, M. \& Stubbe, J. (1994). Overexpression and purification of the soluble polyhydroxyalkanoate synthase from Alcaligenes eutrophus - evidence for a required posttranslational modification for catalytic activity. Biochemistry 33, 9311-9320.

Handrick, R., Reinhardt, S. \& Jendrossek, D. (2000). Mobilization of poly(3-hydroxybutyrate) in Ralstonia eutropha. J Bacteriol 182, 5916-5918.

Haywood, G. W., Anderson, A. J., Williams, G. A., Dawes, E. A. \& Ewing, D. F. (1991). Accumulation of a poly(hydroxyalkanoate) copolymer containing primarily 3-hydroxyvalerate from simple carbohydrate substrates by Rhodococcus sp. NCIMB 40126. Int J Biol Macromol 13, 83-88.

Hoffmann, N., Steinbüchel, A. \& Rehm, B. H. A. (2000a). The Pseudomonas aeruginosa phaG gene product is involved in the synthesis of polyhydroxyalkanoic acid consisting of mediumchain-length constituents from non-related carbon sources. FEMS Microbiol Lett 184, 253-259.

Hoffmann, N., Steinbüchel, A. \& Rehm, B. H. A. (2000b). Homologous functional expression of cryptic pha G from Pseudomonas oleovorans establishes the transacylase-mediated polyhydroxyalkanoate biosynthetic pathway. Appl Microbiol Biotechnol 54, 665-670.

Hoppensack, A., Rehm, B. H. A. \& Steinbüchel, A. (1999). Analysis of 4-phosphopantetheinylation of polyhydroxybutyrate synthase from Ralstonia eutropha: generation of beta-alanine auxotrophic $\mathrm{Tn} 5$ mutants and cloning of the panD gene region. J Bacteriol 181, 1429-1435. 
Jia, Y., Kappock, T. J., Frick, T., Sinskey, A. J. \& Stubbe, J. (2000). Lipases provide a new mechanistic model for polyhydroxybutyrate (PHB) synthases: characterization of the functional residues in Chromatium vinosum $\mathrm{PHB}$ synthase. Biochemistry 39, 3927-3936.

Jia, Y., Yuan, W., Wodzinska, J., Park, C., Sinskey, A. J. \& Stubbe, J. (2001). Mechanistic studies on class I polyhydroxybutyrate (PHB) synthase from Ralstonia eutropha: class I and III synthases share a similar catalytic mechanism. Biochemistry 40, 1011-1019.

Kovach, M. E., Elzer, P. H., Hill, D. S., Robertson, G. T., Farris, M. A., Roop, R. M. \& Peterson, K. M. (1995). 4 new derivatives of the broad-host-range cloning vector pBBR1MCS, carrying different antibiotic-resistance cassettes. Gene 166, 175-176.

Laemmli, U. K. (1970). Cleavage of structural proteins during the assembly of the head of bacteriophage T4. Nature 227, 680-685.

Langenbach, S., Rehm, B. H. A. \& Steinbüchel, A. (1997). Functional expression of the PHA synthase gene phaC1 from Pseudomonas aeruginosa in Escherichia coli results in poly(3hydroxyalkanoate) synthesis. FEMS Microbiol Lett 150, 303-309.

Liebergesell, M., Sonomoto, I. L., Madkour, M., Mayer, F. \& Steinbüchel, A. (1994). Purification and characterization of the poly(hydroxyalkanoic acid) synthase from Chromatium vinosum and localization of the enzyme at the surface of poly(hydroxyalkanoic acid) granules. Eur J Biochem 226, 71-80.

Mak, Y. M. \& Ho, K. K. (1993). An improved procedure for direct phenol extraction of single-stranded M13-DNA for sequencing. Biotechniques 14, 732-734.

Nierman, W. C., Feldblyum, T. V., Laub, M. T. \& $\mathbf{3 4}$ other authors (2001). Complete genome sequence of Caulobacter crescentus. Proc Natl Acad Sci US A 98, 4136-4141.

Peoples, O. P. \& Sinskey, A. J. (1989a). Poly- $\beta$-hydroxybutyrate biosynthesis in Alcaligenes eutrophus H16 - characterization of the genes encoding $\beta$-ketothiolase and acetoacetyl-CoA reductase. J Biol Chem 264, 15293-15297.

Peoples, O. P. \& Sinskey, A. J. (1989b). Poly- $\beta$-hydroxybutyrate biosynthesis in Alcaligenes eutrophus $\mathrm{H} 16$ - identification and characterization of the PHB polymerase gene $(p h b C) . J$ Biol Chem 264, 15298-15303.

Poindexter, J. S. (1981). The Caulobacters - ubiquitous unusual bacteria. Microbiol Rev 45, 123-179.

Qi, Q. S., Rehm, B. H. A. \& Steinbüchel, A. (1997). Synthesis of poly(3-hydroxyalkanoates) in Escherichia coli expressing the PHA synthase gene phaC2 from Pseudomonas aeruginosa: comparison of PhaC1 and PhaC2. FEMS Microbiol Lett 157, $155-162$.

Qi, Q. S., Steinbüchel, A. \& Rehm, B. H. A. (1998). Metabolic routing towards polyhydroxyalkanoic acid synthesis in recombinant Escherichia coli ( $\mathrm{fadR})$ : inhibition of fatty acid betaoxidation by acrylic acid. FEMS Microbiol Lett 167, 89-94.

Qi, Q., Steinbüchel, A. \& Rehm, B. H. A. (2000). In vitro synthesis of poly (3-hydroxydecanoate) : purification and enzymatic characterization of type II polyhydroxyalkanoate synthases PhaC1 and PhaC2 from Pseudomonas aeruginosa. Appl Microbiol Biotechnol 54, 37-43.

Rehm, B. H. A. \& Steinbüchel, A. (1999). Biochemical and genetic analysis of PHA synthases and other proteins required for PHA synthesis. Int J Biol Macromol 25, 3-19.
Rehm, B. H. A. \& Steinbüchel, A. (2001a). Heterologous expression of the acyl-acyl carrier protein thioesterase gene from the plant Umbellularia californica mediates polyhydroxyalkanoate biosynthesis in recombinant Escherichia coli. Appl Microbiol Biotechnol 55, 205-209.

Rehm, B. H. A. \& Steinbüchel, A. (2001b). PHA synthases - the key enzymes of PHA synthesis. In Handbook 'Biopolymers'. Edited by A. Steinbüchel \& Y. Doi. Weinheim: Wiley-VCH (in press).

Rehm, B. H. A., Krüger, N. \& Steinbüchel, A. (1998). A new metabolic link between fatty acid de novo synthesis and polyhydroxyalkanoic acid synthesis - the phaG gene from Pseudomonas putida KT2440 encodes a 3-hydroxyacyl-acyl carrier protein coenzyme A transferase. J Biol Chem 273, 24044-24051.

Rehm, B. H. A., Qi, Q. S., Beermann, B. B., Hinz, H.-J. \& Steinbüchel, A. (2001a). Matrix-assisted in vitro refolding of Pseudomonas aeruginosa class II polyhydroxyalkanoate synthase from inclusion bodies produced in recombinant Escherichia coli. Biochem J 358, 263-268.

Rehm, B. H. A., Hoffmann, N., Qi, Q., Fiedler, S. \& Steinbüchel, A. (2001b). Biosynthesis of latex-like polyhydroxyalkanoates. In Proceedings of the International Symposium on Bioconversion of Renewable Raw Materials. Braunschweig, Germany: GBF (in press).

Sambrook, J., Fritsch, E. F. \& Maniatis, T. (1989). Molecular Cloning: a Laboratory Manual, 2nd edn. Cold Spring Harbor, NY : Cold Spring Harbor Laboratory.

Schlegel, H. G., Lafferty, R. \& Krauss, I. (1970). The isolation of mutants not accumulating poly-beta-hydroxybutyric acid. Arch Microbiol 71, 283-294.

Schubert, P., Steinbüchel, A. \& Schlegel, H. G. (1988). Cloning of the Alcaligenes eutrophus genes for synthesis of poly- $\beta$ hydroxybutyric acid (PHB) and synthesis of PHB in Escherichia coli. J Bacteriol 170, 5837-5847.

Schubert, P., Krüger, N. \& Steinbüchel, A. (1991). Molecular analysis of the Alcaligenes eutrophus poly(3-hydroxybutyrate) biosynthetic operon - identification of the N-terminus of poly(3hydroxybutyrate) synthase and identification of the promoter. $J$ Bacteriol 173, 168-175.

Simon, R., Priefer, U. \& Pühler, A. (1983). A broad host range mobilization system for in vivo gentetic engineering - transposon mutagenesis in Gram-negative bacteria. Bio/Technology 1, 784-791.

Spiekermann, P., Rehm, B. H. A., Kalscheuer, R., Baumeister, D. \& Steinbüchel, A. (1999). A sensitive, viable-colony staining method using Nile red for direct screening of bacteria that accumulate polyhydroxyalkanoic acids and other lipid storage compounds. Arch Microbiol 171, 73-80.

Valentin, H. E. \& Steinbüchel, A. (1993). Cloning and characterization of the Methylobacterium extorquens polyhydroxyalkanoic-acid-synthase structural gene. Appl Microbiol Biotechnol 39, 309-317.

Received 11 June 2001; revised 30 July 2001; accepted 14 August 2001. 